\title{
Some Notes on Relative Commutators
}

\author{
Masoumeh Ganjali and Ahmad Efranian* \\ Department of Pure Mathematics and Center of Excellence in Analysis on Algebraic Structures, \\ Fedowsi University of Mashhad, P.O.Box 1159-91775 Mashhad, Iran \\ Email: m.ganjali20@yahoo.com, *erfanian@math.um.ac.ir
}

\begin{abstract}
Let $G$ be a group and $\alpha \in \operatorname{Aut}(G)$. An $\alpha$-commutator of elements $x, y \in G$ is defined as $[x, y]_{\alpha}=x^{-1} y^{-1} x y^{\alpha}$. In 2015, Barzegar et al. introduced an $\alpha$-commutator of elements of $G$ and defined a new generalization of nilpotent groups by using the definition of $\alpha$ commutators which is called an $\alpha$-nilpotent group. They also introduced an $\alpha$-commutator subgroup of $G$, denoted by $D_{\alpha}(G)$ which is a subgroup generated by all $\alpha$-commutators. In 2016, an $\alpha$-perfect group, a group that is equal to its $\alpha$-commutator subgroup, was introduced by authors of this paper and the properties of such group was investigated. They proved some results on $\alpha$-perfect abelian groups and showed that a cyclic group $G$ of even order is not $a$ perfect for any $\alpha \in A u t(G)$. In this paper, we may continue our investigation on $\alpha$-perfect groups and in addition to studying the relative perfectness of some classes of finite $p$-groups, we provide an example of a non-abelian $\alpha$-perfect 2 -group.

Keywords: Auto-commutator subgroup; finite $p$-group; normal subgroup; perfect group.
\end{abstract}

\begin{abstract}
Abstrak
Misalkan $G$ grup dan $\alpha \in \operatorname{Aut}(G)$. Suatu $\alpha$-komutator dari unsur-unsur $x, y \in G$ didefinisikan sebagai $[x, y]_{\alpha}=x^{-1} y^{-1} x y^{\alpha}$. Pada tahun 2015, Barzegar et al. memperkenalkan $\alpha$ komutator dari unsur-unsur di $G$ dan mendefinisikan sebuah perumuman baru dari grup-grup nilpoten dengan menggunakan definisi dari $\alpha$-komutator yang dinamakan grup $\alpha$-nilpoten. Mereka juga memperkenalkan suatu subgrup $\alpha$-komutator dari $G$ yang dilambangkan dengan $D_{\alpha}(G)$ yang merupakan subgrup yang dibangun dari semua $\alpha$-komutator. Pada tahun 2016, grup $\alpha$-sempurna, yaitu grup yang subgrup $\alpha$-komutatornya sama dengan grup itu sendiri, diperkenalkan oleh penulis paper ini dan sifat-sifat grup tersebut juga diselidiki. Mereka membuktikan beberapa sifat dari grup abel $\alpha$-sempurna dan memperlihatkan bahwa suatu grup siklis $G$ dengan order genap bukan grup $a$-sempurna untuk setiap $\alpha \in \operatorname{Aut}(G)$. Di paper ini kita akan melanjutkan investigasi kita pada grup-grup $\alpha$-sempurna dan sebagai tambahan dalam mempelajari kesempurnaan relatif dari kelas-kelas dari $p$-grup berhingga, kita akan melihat contoh dari 2-grup $\alpha$-sempurna yang non abel.
\end{abstract}

Kata kunci: subgrup auto-komutator; $p$-grup berhingga; subgrup normal; grup sempurna.

Mathematics Subject Classification (2010): Primary 20F12; Secondary 20 D45. 


\section{INTRODUCTION}

In 1994, an auto-commutator $[x, \alpha]=x^{-1} x^{\alpha}$ of elements $x \in G$ and $\alpha \in \operatorname{Aut}(G)$ was introduced by Hegarty, [1]. If $\alpha_{g}$ is an inner automorphism such that $x^{\alpha g}=g^{-1} x g$ then auto-commutator $\left[x, \alpha_{g}\right]=x^{-1} g^{-1} x g$ is the ordinary commutator of two elements $x, g \in$ $G$. Hegarty generalized the definition of the center of $G, Z(G)=\left\{x \in G: x^{\alpha y}=x, \forall y \in G\right\}$ to the absolute center $L(G)=\left\{x \in G: x^{\alpha}=x, \forall \alpha \in \operatorname{Aut}(G)\right\}$ of $G$. One can check that $L(G)$ is an characteristic subgroup of $G$ which is contained in $Z(G)$. He also introduced the autocommutator subgroup of $G$, denoted by $K(G)$, which is a characteristic subgroup generated by all auto-commutators. Clearly, the commutator subgroup $G^{\prime}$ is contained in $K(G)$. Investigation of the relative commutators are interesting for some authors, for instance Barzegar et al. [2] also introduced a new generalization of commutators with respect to a fixed automorphism of group $G$. Let $\alpha \in \operatorname{Aut}(G)$, then an $\alpha$-commutator of two elements $x, g \in G$ is defined as $[x, y]_{\alpha}=x^{-1} y^{-1} x y^{\alpha}$ which is equal to the ordinary commutator $[x, y]=x^{-1} y^{-1} x y$ whenever $\alpha$ is the identity automorphism. In [2], the subgroup which is generated by all $\alpha$-commutators was denoted by $D_{\alpha}(G)$ and called $\alpha$-commutator subgroup of $G$. It is not difficult to prove that $D_{\alpha}(G)$ is a normal subgroup of $G$ that is contained in $K(G)$. Authors of [2] also introduced a new generalization of a nilpotent group $G$, which is called an $\alpha$-nilpotent group for a fixed automorphism $\alpha$ of $G$. Here, we may present the definition of an $\alpha$-nilpotent group $G$. We start by the definition of a lower central $\alpha$-series. Put $\Gamma_{1}^{\alpha}(G)=G \quad$ and $\quad \Gamma_{2}^{\alpha}(G)=D_{\alpha}(G) \quad$ and define inductively $\Gamma_{n+1}^{\alpha}(G)=\left[G, \Gamma_{n}^{\alpha}(G)\right]_{\alpha}=\left\langle[x, y]_{\alpha}: x \in G, y \in \Gamma_{n}^{\alpha}(G)\right\rangle, n \geq 1$. We can see that $\Gamma_{n}^{\alpha}(G)$ is a normal subgroup of $G$ which is invariant under $\alpha$ and $\Gamma_{n+1}^{\alpha}(G) \leq \Gamma_{n}^{\alpha}(G)$, for all $n \geq 1$. Following normal series is called a lower central $\alpha$-series $G \geq \Gamma_{2}^{\alpha}(G) \geq \cdots \geq \Gamma_{n}^{\alpha}(G) \geq \cdots$.

A group $G$ is called an $\alpha$-nilpotent group of nilpotency class $n$ if $\Gamma_{n}^{\alpha}(G)=\{1\}$ and $\Gamma_{n+1}^{\alpha}(G) \neq\{1\}$. Clearly, if $\alpha$ is considered as the identity automorphism, then an $\alpha$-nilpotent group is the ordinary one. In [2], it was proved that an $\alpha$-nilpotent group is nilpotent, but the converse is not valid in general. For instance, authors proved that the cyclic group of order $n=p_{1} p_{2} \ldots p_{t}$ is $\alpha$-nilpotent if and only if $\alpha$ is the identity automorphism, for distinct primes $p_{1}, p_{2}, \ldots, p_{t}$. Authors of [3] continued investigation on $\alpha$-nilpotent groups and proved some new results on this new concept. For example, they proved that an extra special $p$-group, $p$ is an odd prime number, is nilpotent with respect to a non-identity automorphism $\alpha$ but is not nilpotent relative to all its automorphisms. For an inner automorphism $\alpha_{g} \in \operatorname{Inn}(G)$, we can see that nilpotency and $\alpha_{g}$-nilpotency are equivalent. Therefore, we may ask the following question.

Question. Is there a non-inner automorphism $\alpha$ of nilpotent group $G$ such that $G$ is $\alpha$-nilpotent? 
This question was answered for finitely generated abelian groups, for more details see [3]. Actually, authors classified all finitely generated abelian groups which are nilpotent with respect to a non-inner automorphism. Furthermore, they proved some results on relative normal and absolute normal subgroups of some classes of finite groups. In [4], they introduced an $\alpha$-perfect group $G$, a group which is equal to its $\alpha$-commutator subgroup, for a fixed automorphism $\alpha$ of $G$. If $G^{\prime}$ is the ordinary commutator subgroup of $G$, then $G^{\prime} \leq D_{\alpha}(G)$ for all $\alpha \in \operatorname{Aut}(G)$. It follows that if $G$ is a perfect group, then it is perfect with respect to all its automorphisms. One can check that an $\alpha$-nilpotent group cannot be $\alpha$-perfect, but the symmetric group of order $n !, S_{n}$ is an example of a non-nilpotent group where is not $\alpha$-perfect, because $D_{\alpha}\left(S_{n}\right)=\left(S_{n}\right)^{\prime}=A_{n}$ for all $\alpha \in \operatorname{Aut}(G)$. The relative perfectness of abelian groups was studied by authors of [4]. In this paper, we may continue our investigation on relative perfect groups and prove some new results on some classes of finite non-abelian $p$-groups.

\section{RELATIVE PERFECT GROUPS}

In this section, we recall the definition of an $\alpha$-perfect group for a fixed automorphism $\alpha$. At first, we present some results on relative perfect groups that were proved in [4]. Finally, we may add some new results on non-abelian relative perfect groups.

Definition 2.1. Let $G$ be a group and $\alpha \in \operatorname{Aut}(G)$. A group $G$ is called an $\alpha$-perfect group, whenever $G=D_{\alpha}(G)$.

Definition 2.2. If $G$ is a finite group and $\alpha \in \operatorname{Aut}(G)$, then a subgroup $H$ of $G$ is called an $\alpha$-normal subgroup of $G$, denoted by $H \unlhd \stackrel{\alpha}{\unlhd}$, if $g^{-1} h g^{\alpha} \in H$ for all $g \in G$ and $h \in H$. If $H$ is $\alpha$-normal with respect to all automorphisms $\alpha \in \operatorname{Aut}(G)$, then $G$ is called an absolute normal subgroup of $G$.

Lemma 2.3. ( [4] ) Let $H$ be a subgroup of finite group $G$, then (i) if there exists an $\alpha \in A u t(G)$ such that $H \unlhd G$, then $H$ is a normal subgroup of $G$, (ii) $H$ is an absolute normal subgroup of $G$ if and only if $K(G) \leq H$.

It might be important to find all proper absolute normal subgroups of given finite group $G$. In [3] and [4], the structure of absolute normal subgroups of some classes of finite groups were given. For instance, we have the following results.

Lemma 2.4. ( $[4]$ ) If $G \cong Z_{2^{n} m}$ such than $(2, m)=1$, then the proper subgroup $H$ of $G$ is absolute normal if and only if $H=2 G$.

Theorem 2.5. ( [3] ) (i) If $D_{2 n}=\left\langle x, y: x^{n}=y^{2}=1, y x y=x^{-1}\right\rangle$, then $\langle x\rangle$ is the only proper absolute normal subgroup of $D_{2 n}$. (ii) Semi-dihedral 2-group $S D_{2^{n+1}}=\left\langle x, y: x^{2 n}=y^{2}=1, y x y=x^{-1}=x^{2^{n-1}-1}\right\rangle, n \geq 3$ has the only proper absolute normal subgroups given by $\langle x\rangle,\left\langle x^{2}\right\rangle,\left\langle x^{2}, y\right\rangle,\left\langle x^{2}, y x\right\rangle$. (iii) Generalized 
quaternion 2-group $Q_{2^{n+1}}=\left\langle x, y: x^{2 n}=1, x^{2 n-1}=y^{2}, y x y^{-1}=x^{-1}\right\rangle, n \geq 3$ has the only proper absolute normal subgroup $\langle x\rangle$. (iv) Twisted dihedral 2-group $S_{*} D_{2^{n+1}}=\left\langle x, y: x^{2 n}=y^{2}=1, y x y^{-1}=x^{2^{n-1}+1}\right\rangle, n \geq 3$ has the only proper absolute normal subgroup $\left\langle x^{2}, y\right\rangle$.

Theorem 2.6. ( [3] ) If $p$ is an odd prime number and $M_{n}(p)=\left\langle x, y: x^{p^{n-1}}=y^{p}=1, x y=y x^{p^{n-2}+1}\right\rangle$, $n \geq 3$, then $M_{n}(p)$ does not possess a proper absolute normal subgroup.

Next lemma, talks about the existence of an $\alpha$-normal subgroup in abelian $\alpha$-perfect group $G$.

Lemma 2.7. ( [4] ) Let $G$ be a finite abelian group. Then $G$ is $\alpha$-perfect if and only if $G$ does not possess a proper $\alpha$-normal subgroup.

If $G$ is a finite cyclic group of order $n$, then $\alpha \in \operatorname{Aut}(G)$ if and only if $x^{\alpha}=u x$ such that $(u, n)=1$, for all $x \in G$. We denote such $\alpha$ by $\alpha_{u}$.

Lemma 2.8. ( [4] ) Let $G$ be a cyclic group of order $n$ and $\alpha_{u} \in \operatorname{Aut}(G)$ be a non-identity automorphism. Then $G$ is $\alpha_{u}$-perfect if only if $(u-1, n)=1$.

By Lemma 2.8, we can conclude that there is no $\alpha$-perfect cyclic group of even order, for all automorphisms $\alpha$ of such group. If $p$ is an odd prime number, then $\mathrm{Z}_{p^{r}}, r>1$, is $\alpha_{u^{-}}$ perfect for each $1<u<p$, but it is not $\alpha_{p+1}$-perfect.

Now, we are ready to prove some new results on relative perfect groups.

Lemma 2.9. If $\alpha_{g}$ is an inner automorphism and $\beta=\alpha \circ \alpha_{g}$, then $G$ is $\alpha$-perfect if and only if is $\beta$ perfect.

Proof. We can see that $[x, y]_{\beta}=[x, y]_{\alpha}[y, g]^{\alpha}$ and since $[y, g] \in G^{\prime} \leq D_{\alpha}(G)$ and $D_{\alpha}(G)$ is $\alpha$-invariant, then $[x, y]_{\beta} \in D_{\alpha}(G)$ and so $D_{\beta}(G) \leq D_{\alpha}(G)$. We can write $\alpha=\beta \circ \alpha_{g}^{-1}$ and prove $D_{\alpha}(G) \leq D_{\beta}(G)$. Now, we are done.

Example 2.10. (i) If $G$ is isomorphic to one of the groups where are defined in Theorem 2.5 , then $G$ possesses a proper absolute normal subgroup. Furthermore, we know that $D_{\alpha}(G) \leq K(G)$, for all $\alpha \in \operatorname{Aut}(G)$. So by Lemma 2.3, $D_{\alpha}(G)$ is a proper subgroup of $G$ and $G$ is not $\alpha$-perfect for any $\alpha \in \operatorname{Aut}(G)$. (ii) Assume that that $Q_{8}=\left\langle x y: x^{4}=1, x^{2}=y^{2}, y x y^{-1}=x^{-1}\right\rangle, n \geq 3$ and $\alpha \in \operatorname{Aut}\left(Q_{8}\right)$ is an automorphism by argument $x^{\alpha}=y$ and $y^{\alpha}=x y$. Then $D_{\alpha}\left(Q_{8}\right)=Q_{8}$ and $Q_{8}$ is an $\alpha$-perfect group. 
By Theorem 2.6, if $G \cong M_{n}(p)$, then $G$ does not possess any proper absolute normal subgroup. Here, we may prove that $M_{n}(p)$ is not $\alpha$-perfect for any $\alpha \in \operatorname{Aut}(G)$.

Theorem 2.11. If $G \cong M_{n}(p)=\left\langle x, y: x^{p^{n-1}}=y^{p}=1, x y=y x^{p^{n-2}+1}\right\rangle$ for an odd prime number $p$ and $n \geq 3$, then $G$ is not $\alpha$-perfect for any $\alpha \in \operatorname{Aut}(G)$.

Proof. We can see that $|G|=p^{n}, Z(G)=\left\langle x^{p}\right\rangle, G^{\prime}=\left\langle x^{p^{n-2}}\right\rangle$. The automorphism group of $G$, $\operatorname{Aut}(G)$ is equal to $\left\{\alpha_{i j k}: x^{\alpha_{i j k}}=x^{i} y^{j}, y^{\alpha_{j k}}=x^{k p^{n-2}} y, 0 \leq i \leq p^{n-1}-1, i \neq 0,0 \leq j, k \leq p-1\right\}$. It is not difficult to see that $[x, x]_{\alpha_{i j k}}=x^{i-1} y^{j},[x, y]_{\alpha_{i j k}}=x^{(k+1) p^{n-2}},[y, x]_{\alpha_{i j k}}=x^{p^{n-2}} x^{i-1} y^{j},[y, y]_{\alpha_{i j k}}=x^{k p^{n-2}}$. Therefore, $D_{\alpha_{i j k}}(G)=\left\langle x^{i-1} y^{j}, x^{p^{n-2}}\right\rangle$. If $i \neq 1$, then $\left|x^{i-1} y^{j}\right|=|x|$, also $(i-1) p^{n-2} \stackrel{p^{n-1}}{\equiv} p^{n-2}$ and for a positive integer $m$ we have $\left(x^{i-1} y^{j}\right)^{m}=x^{m(i-1)-(i-1) j\left(\frac{m(m-1)}{2}\right) p^{n-2} y^{m j}}$.

Now, if we put $m=p^{n-2}$, then since $n \geq 3, p^{n-2} \geq p$ and $\left(x^{i-1} y^{j}\right) p^{n-2}=x^{(i-1) p^{n-2}}=x^{p^{n-2}}$. It means that $x^{p^{n-2}} \in\left\langle x^{i-1}, y^{j}\right\rangle$ and $D_{\alpha i j}(G) \in\left\langle x^{i-1}, y^{j}\right\rangle$ is a proper subgroup of $G$, because $\left|x^{i-1} y^{j}\right|=p^{n-1}$. Now if, $i=1$ and $j \neq 0$, then $D_{\alpha i j}(G) \in\left\langle y^{j}, x^{p^{n-2}}\right\rangle$ and since $\left|y^{j}\right|=\left|x^{p^{n-1}}\right|=p$, then $D_{\alpha i j}(G) \neq G$. In case $j=0$, we have $D_{\alpha i j}(G)=G^{\prime} \neq G$. If $i \neq 1$ and $i \stackrel{p}{\equiv} 1$ then $i=1+l p^{s}$, where $(l, p)=1, s=1,2, \ldots, n-2$. In this case, $G$ is $\alpha_{i j k}$-nilpotent by Theorem 4.10 of [2] and so $D_{\alpha_{i j k}}(G) \neq G$. Hence, we are finished.

Theorem 2.12. Let $p$ be an odd prime number. If $G=\left\langle a, b: a^{p^{2}}=b^{p^{3}}=1, a^{-1} b a=b^{p+1}\right\rangle$ is a $p$ group of order $p^{5}$ and nilpotency class three, then $G$ is not $\alpha$-perfect for any $\alpha \in \operatorname{Aut}(G)$.

Proof. The automorphism group of $\quad G \quad$ is $\operatorname{Aut}(G)=\left\{\alpha_{z, \omega, \mu}: a^{\alpha_{z, \omega, \mu}}=a\left(a^{z} b^{\omega}\right)^{\mu}, b^{\alpha_{z, \omega, \mu}}\right.$ $\left.=a^{z} b^{\omega} ; z p \stackrel{p^{2}}{\equiv} 0, \omega \neq 0, \mu p^{2} \stackrel{p^{3}}{\equiv} 0\right\}$. Let $\alpha=\alpha_{z, \omega, \mu} \in \operatorname{Aut}(G)$, be an arbitrary automorphism such that $z=p t$ and $\quad \mu=p k$ for some integers $t, k \in \mathrm{Z}$. Then (i) $[a, a]_{\alpha}=\left(a^{p t} b^{\omega}\right)^{p k}=a^{p^{2} t k} b^{\omega \frac{(p+1)^{p^{2} t k}-1}{(p+1)^{p t k}-1}}=b^{\omega \frac{(p+1)^{p^{2} t k}-1}{(p+1)^{p t k}-1}}$, (ii) $\quad[a, b]_{\alpha}=a^{-1} b^{-1} a a^{p t} b^{\omega}=a^{-1} a b^{-p-1} a^{p t} b^{\omega}$ $=b^{p t+\omega-p-1}$, (iii) $[b, a]_{\alpha}=b^{-1} a^{-1} b a\left(a^{p t} b^{\omega}\right)^{p k}=b^{p} b^{\omega \frac{(p+1)^{p^{2} t k}-1}{(p+1)^{p t k}-1}}$, and (iv) $[b, b]_{\alpha}=b^{-1} a^{p t} b^{\omega}=a^{p t} b^{-(p+1)^{p t}}$ $=a^{p t} b^{-\left(p^{2} t+1\right)}$. 
Assume that $\alpha \in D_{\alpha}(G)$, then there exists an integer $j$ such that $a=\left(a^{p t} b^{-\left(p^{2} t+1\right)}\right)^{j}$. Put $m=\frac{(p+1)^{p t j}-1}{(p+1)^{p t}-1}$, then since $Z(G)=\left\langle b^{p^{2}}\right\rangle$ we have $a=\left(a^{p t} b^{-1}\right)^{j} b^{-p^{2} t j}$ and $a^{p t j} b^{-m} b^{-p^{2} t j}=a$. We know that $b a=a b^{p+1}$, so we can conclude that $b a^{p t} b^{-m} b^{-p^{2} t j}=a^{p t j} b^{-m} b^{-p^{2} t j} b^{p+1}$, and so $a^{p t j} b^{(p+1)^{p t j}} b^{-m}=a^{p t j} b^{-m} b^{p+1}$ and $\quad b^{(p+1)^{p t j}}=b^{p+1}$. But $\quad b^{(p+1)^{p t j}}=b^{p^{2} t j+1}$, therefore $\quad$ we $\quad$ have $b^{p^{2} t j+1}=b^{p+1}$ and $b^{p^{2} t j-p}=1$ which implies that $p^{3} \mid p^{2} t j-p$, a contradiction. Hence $D_{\alpha}(G)<G$ and $G$ is not $\alpha$-perfect.

In [4], has been shown that for every finite abelian group $G$, there exists a finite abelian group $H$ and $\alpha \in \operatorname{Aut}(H)$ such that $D_{\alpha}(H) \cong G$. Here, we may improve this result to finitely generated abelian groups.

Proposition 2.13. If $\alpha \in A u t(G)$ and $\beta \in A u t(H)$, then $D_{\alpha \times \beta}(G \times H)=D_{\alpha}(G) \times D_{\beta}(H)$.

Proof. It is straightforward.

Theorem 2.14. Assume that $G=\underbrace{\mathrm{Z} \times \mathrm{Z} \times \cdots \times \mathrm{Z}}_{t \text {-times }} \times G_{1}$ such that $G_{1}$ is a finite abelian group. Then there exist an abelian group $H$ and $\alpha \in A u t(H)$ such that $D_{\alpha}(H) \cong G$.

Proof. By Theorem 3.7 of [4], for finite group $G_{1}$, there exist abelian group $H_{1}$ and $\beta \in \operatorname{Aut}\left(H_{1}\right)$ such that $D_{\beta}\left(H_{1}\right) \cong G_{1}$. Now, if $\alpha_{i} \in \operatorname{Aut}\left(\mathrm{Z}_{i} \times \mathrm{Z}_{i}\right)$ by argument $(a, b)^{\alpha_{i}}=(a+b, b)$, then $D_{\alpha_{i}}\left(\mathrm{Z}_{i} \times \mathrm{Z}_{i}\right)=\left\langle-(a, b)+(a, b)^{\beta}: a, b \in \mathrm{Z}_{i}\right\rangle=\left\langle(b, 0): b \in \mathrm{Z}_{i}\right\rangle \cong \mathrm{Z}$, where $\mathrm{Z}_{i} \cong \mathrm{Z}$ for $i=1, \ldots, t$. Now, it is enough to put $H=\underbrace{\mathrm{Z} \times \mathrm{Z} \times \cdots \times \mathrm{Z}}_{2 t \text {-times }} \times H_{1}$ and $\alpha=\alpha_{1} \times \cdots \times \alpha_{t} \times \beta$, then $D_{\alpha}(H)=D_{\alpha_{1}}(\mathrm{Z} \times \mathrm{Z})$ $\times D_{\alpha_{2}}(\mathrm{Z} \times \mathrm{Z}) \times \cdots \times D_{\alpha_{t}}(\mathrm{Z} \times \mathrm{Z}) \times D_{\beta}\left(H_{1}\right) \cong G$, and the proof is completed

\section{REFERENCES}

[1] P. Hegarty, "The absolute centre of a group," J. Algebra, vol. 169, p. 929-935, 1994.

[2] R. Barzegar and A. Erfanian, "Nilpotency and solubility of groups relative to an automorphism," Caspian J. Math. Sci., vol. 4, no. 2, pp. 271-281, 2015.

[3] A. Erfanian and M. Ganjali, "Nilpotent groups related to an automorphism," Proc. Indian Acad. Sci. (Math. Sci.), vol. 128:60, pp. 1-12, 2018.

[4] M. Ganjali and A. Erfanian, "Perfect groups and normal subgroups related to an automorphism," Ricerche Mat, pp. 1-7, 2016. 